\title{
Erratum to: Low Velocity Impact Behavior of Basalt Fiber-Reinforced Polymer Composites
}

Farzin Azimpour Shishevan, Hamit Akbulut, and M.A. Mohtadi-Bonab

(published online June 27, 2017)

Erratum to: JMEPEG (2017) 26:2890-2900

DOI 10.1007/s11665-017-2728-1

Please note that the first name of coauthor Hamit Akbulut is misspelled in this article (it is given as "Hamid" rather than as "Hamit").

The online version of the original article can be found under doi: 10.1007/s11665-017-2728-1.

Farzin Azimpour Shishevan and Hamit Akbulut, Department of Mechanical Engineering, Ataturk University, Erzurum, Turkey; and M.A. Mohtadi-Bonab, Department of Mechanical Engineering, University of Bonab, Velayat Highway, Bonab, Iran. Contact e-mail: m.mohtadi@usask.ca. 